\title{
Digital ischaemia after intra-arterial drug injection
}

\author{
Michael James Neuss, ${ }^{1}$ Thomas Lawrence Holland ${ }^{2}$
}

${ }^{1}$ Department of Internal Medicine, Vanderbilt University, Nashville, Tennessee, USA ${ }^{2}$ Division of Infectious Diseases, Department of Medicine, Duke University Medical Center, Durham, North Carolina, USA

\section{Correspondence to} Dr Michael James Neuss, michael.j.neuss@vanderbilt.edu

Accepted 12 September 2017

\section{DESCRIPTION}

A 62-year-old man presented with recurrent episodes of left-sided digital ischaemia (figure 1). His history was significant for chronic back pain and prescription opiate use. One year previously, he had an episode of ischaemia involving the left hand, requiring amputation of the left thumb and index finger. One month prior, he developed ischaemic

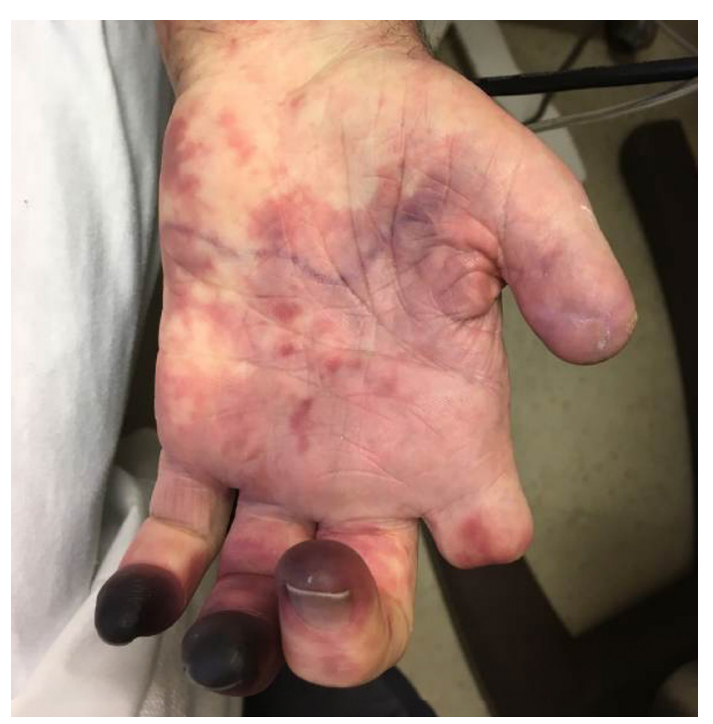

Figure 1 Photograph of left hand showing digital necrosis, prior thumb and index finger partial amputations, and mottling of the palm.

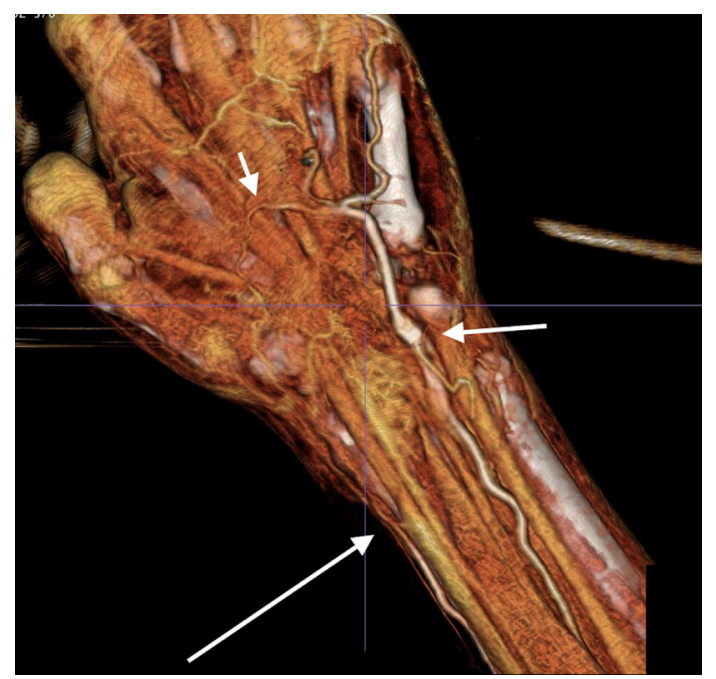

Figure 2 Three-dimensional reconstruction of left upper extremity CT angiography. The radial artery (long arrow) is obstructed and the ulnar artery (short arrow) is hypertrophied. There is poor flow through the superficial palmar arch (arrowhead).

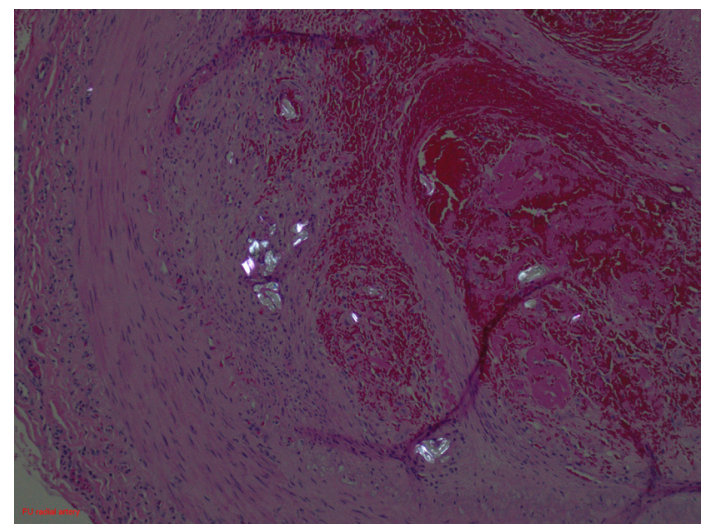

Figure 3 H\&E-stained histological section from a specimen of left radial artery, showing polarisable microcrystalline cellulose pill filler material embedded in remote and subacute thrombus.

\section{Learning points}

- Given the ubiquity of prescription opiates and the approximately 2.5 million people in the USA with opioid addiction, recognition of prescription drug abuse in patients with otherwise unexplained vasculitis or hypercoagulopathy may help clinicians address potentially harmful injection of opiates. $^{1}$

- Biopsy revealed microcrystalline cellulose pill filler material, which is commonly associated with microthrombosis in the lungs of intravenous injection drug users. Digital ischaemia following accidental intra-arterial injection has also been reported. Ischaemia may not be reversible, but cessation of drug injection should prevent further injury. ${ }^{2}$

- Buprenorphine/naloxone is a first-line opioid agonist treatment in patients with a history of injection drug abuse. ${ }^{3}$

digits of the left foot. Extensive serological evaluation of causes of vasculitis and thrombosis was negative. Left upper extremity arteriography demonstrated obstruction of the radial and interosseous arteries (figure 2). The ulnar artery was hypertrophied, suggesting a chronic process. Biopsy of the radial artery revealed polarisable microcrystalline cellulose pill filler material embedded in remote and subacute thrombus (figure 3). When informed of this finding, the patient acknowledged repeated injection of crushed hydromorphone tablets into his arteries over a period of several months after losing venous 
access. He underwent surgery for necrotic digits, enrolled in a substance abuse programme and initiated treatment with buprenorphine/naloxone. He has remained abstinent from injection drug use, and continues to taper his buprenorphine/naloxone.

Contributors MJN and TLH were both involved in the diagnosis, management, review of the literature and writing of the manuscript.

Competing interests None declared.

Patient consent Obtained.

Provenance and peer review Not commissioned; externally peer reviewed. (c) BMJ Publishing Group Ltd (unless otherwise stated in the text of the article) 2017. All rights reserved. No commercial use is permitted unless otherwise expressly granted.

\section{REFERENCES}

1 Hedden SL, Kennet I Lipari R , et al. Center for Behavioral Health Statistics and Quality. Behavioral health trends in the United States: results from the 2014 National Survey on Drug Use and Health. 2015. HHS Publication No SMA 15-Page 2 of 52.3.4927, NSDUH Series H-50. http://www.samhsa.gov/data/

2 Chang MY, Lin JL. Irreversible ischemic hand following intraarterial injection of zolpidem powder. J Toxicol Clin Toxicol 2003;41:1025-8.

3 Dowell D, Haegerich T, Chou R. CDC Guideline for Prescribing Opioids for Chronic Pain - United States, 2016. MMWR Recomm Rep 2016:65:1-49.

Copyright 2017 BMJ Publishing Group. All rights reserved. For permission to reuse any of this content visit

http://group.bmj.com/group/rights-licensing/permissions.

BMJ Case Report Fellows may re-use this article for personal use and teaching without any further permission.

Become a Fellow of BMJ Case Reports today and you can:

- Submit as many cases as you like

- Enjoy fast sympathetic peer review and rapid publication of accepted articles

- Access all the published articles

Re-use any of the published material for personal use and teaching without further permission

For information on Institutional Fellowships contact consortiasales@bmjgroup.com

Visit casereports.bmj.com for more articles like this and to become a Fellow 